\title{
Catalytic Transesterification Routes to Novel Vinyl Glycolate Derivatives of Polyhydric
} Alcohols

\author{
Buendia, Mikkel B.; Daugaard, Anders E.; Riisager, Anders
}

Published in:

Catalysis Letters

Link to article, DOI:

10.1007/s10562-020-03266-0

Publication date:

2021

Document Version

Peer reviewed version

Link back to DTU Orbit

Citation (APA):

Buendia, M. B., Daugaard, A. E., \& Riisager, A. (2021). Catalytic Transesterification Routes to Novel Vinyl Glycolate Derivatives of Polyhydric Alcohols. Catalysis Letters, 1515, 8-16. https://doi.org/10.1007/s10562-02003266-0

\section{General rights}

Copyright and moral rights for the publications made accessible in the public portal are retained by the authors and/or other copyright owners and it is a condition of accessing publications that users recognise and abide by the legal requirements associated with these rights.

- Users may download and print one copy of any publication from the public portal for the purpose of private study or research.

- You may not further distribute the material or use it for any profit-making activity or commercial gain

- You may freely distribute the URL identifying the publication in the public portal

If you believe that this document breaches copyright please contact us providing details, and we will remove access to the work immediately and investigate your claim 
${ }^{1}$ Centre for Catalysis and Sustainable Chemistry, Department of Chemistry, Technical University of Denmark, Kemitorvet, Building 206, 2800 Kgs. Lyngby. E-mail: ar@kemi.dtu.dk, Tel.: +45 45252233.

$5 \quad{ }^{2}$ Department of Chemical and Biochemical Engineering, Technical University of Denmark, Søltofts Plads,

$6 \quad$ Building 227, 2800 Kgs. Lyngby

ORCID IDs: 0000-0002-0627-6310 (Anders E. Daugaard), 0000-0002-7086-1143 (Anders Riisager)

8

\section{Abstract}

Methyl vinyl glycolate (methyl 2-hydroxybut-3-enoate, MVG) has recently become obtainable from Sn catalysed cascade reactions of mono- and disaccharides. The chemical structure of MVG present several options for chemical transformations and has great potential as a renewable platform chemical for industrial added-value compounds within e.g. polymer chemistry. Herein, we report a catalytic benign transesterification method for the synthesis of MVG ester derivatives of trimethylolpropane (TMP) and pentaerythritol (PE). The secondary alcohol group of MVG greatly complicates the reaction and requires a highly selective catalyst to push the reaction towards high conversion while avoiding polymerization. Thus, a range of different catalytic systems, e.g. Candida Antarctica Lipase B (CALB), Brønsted bases/acids, salicylic aldehyde as well as Lewis acids were evaluated for the reaction. Despite the challenges this leads to unique derivatives of TMP and PE with an additional chemical handle compared to classic derivatives like the methacrylate and mercaptopropionate.

\section{Keywords}

Methyl vinyl glycolate, transesterification, trimethylolpropane, Candida Antarctica Lipase B, tin(II) chloride 


\section{Introduction}

The progressing depletion of fossil fuels and increasing environmental concern demands design and development of novel bio-sustainable materials and chemicals. Currently, hemi-cellulose and sugar crops provide great potential as sustainable carbon sources. The ample functionality of biomass-derived sugars permits the synthesis of unique high functionality platform chemicals such as lactic acid, 5hydroxymethylfurfural, trans-2,5-dihydroxy-3-pentenoic acid methyl ester (DPM) and levulinic acid [1]. Unlike biofuels, these novel chemicals find application within niche markets and represent high-margin low-volume products [2].

Methyl vinyl glycolate (MVG) is another very interesting molecule within this type of renewable platform chemicals. Despite MVGs small molecular structure, it possesses multiple functionalities (hydroxyl, vinyl and ester) enabling a range of chemical modifications. Formation of MVG was discovered by Holm, Saravanamurugan and Taarning [3] during examination of chemocatalytic (rather than fermentation) routes for the synthesis of lactic acid derivatives from C6 sugars. The MVG was rationalized to form via an initial retro-aldol reaction, which was supported by employing C4 sugar substrates where high yields, up to $55 \%$, were obtained with Lewis acidic tin-based catalysts. This route of formation was confirmed in a mechanistic study by Dusselier et al. [4].

Applications with MVG are so far relatively uncharted, however, its high functionality makes it interesting as a platform chemical, e.g. within polymer chemistry for the creation of unique materials. In this context, Sølvhøj, Taarning and Madsen [5] investigated both homo- and cross-metathesis reactions of MVG. Moreover, Dusselier et al. have studied the copolymerization of MVG and lactic acid, where an initial hydrolysis of MVG seemed to be necessary for the polymerization process [6]. Likewise, initial hydrolysis was also required when the homo-metathesis product (dimethyl-2,5-dihydroxy-3- 
hexenedioate) of MVG was investigated as a cross-linking agent within poly lactic acid (PLA) systems [7]. Despite these promising initial studies, new applications with MVG must be further developed to allow the compound to become industrially relevant [8]. Hence, as part of our interest in synthesis of bio-based chemicals [9] and design of new coating materials [10], we therefore set out to further develop the chemistry of MVG. Herein, we present the first direct transesterification of MVG for the synthesis of a new class of polyhydric alcohols derivatives; vinyl glycolic functionalized polyhydric alcohols.

MVG can be envisaged as propitious for a novel class of polyhydric alcohol derivatives with advanced functionalities. Typical polyhydric alcohol derivatives like trimethylolpropane (TMP) ester derivatives of tris(3-mercaptopropionate) and triacrylate find use within coating chemistry [11]. These classical derivatives only possess one functional group per branch, which upon curing, is lost. The secondary alcohol group of MVG introduces an additional chemical handle, where further chemical transformations are possible (Scheme 1). The ability to perform such manipulations is potentially highly valuable, as it provides opportunities for property fine-tuning. Accordingly, we anticipate MVG derivatives to find possible use in both coating systems, adhesives or as additives in formulations requiring a hydrophilic surface as well as in applications where functionalization of the hydroxyl groups provide specialized polymer properties.
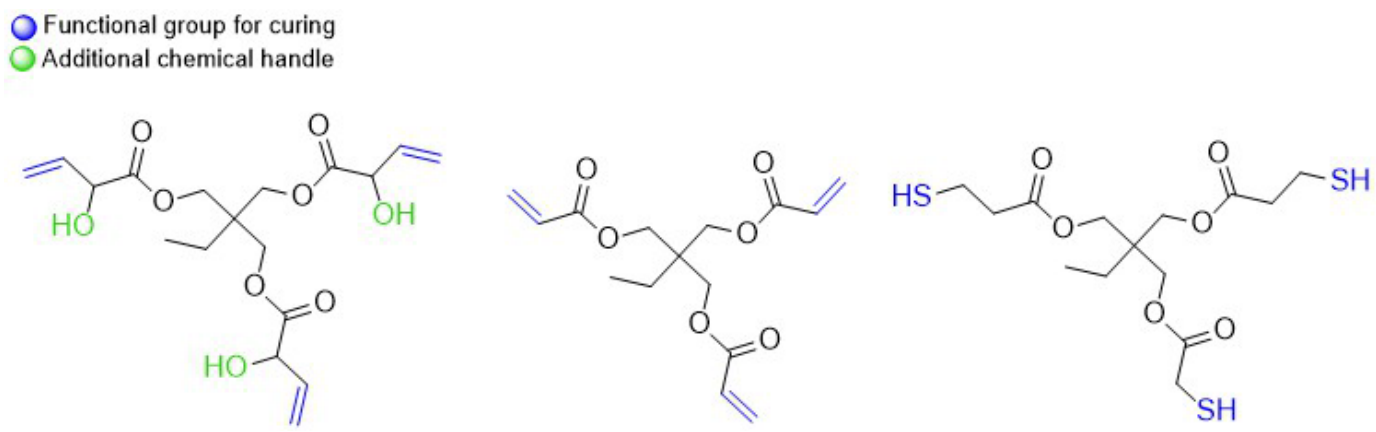
mercaptopropionate (right). 
The synthesis of esters of TMP, and other polyols, are generally straightforward and prepared via a

65 simple esterification process, albeit harsh conditions are necessary. Thus, typically is high temperature as well as reduced pressure along with abundant excess of the corresponding carboxylic acid required to

67 achieve high yields [12][13]. These conditions are, unfortunately, unsuited when utilizing MVG as the

68 secondary alcohol group may induce polymerization, which is further promoted with MVG in large excess.

69 Furthermore, is it considerably more attractive to perform the reaction under stoichiometric conditions.

70

71

72

73

74

75

76

77 transesterifications systems where the hydroxyl group of $\alpha$-hydroxy acid esters evoke complications.
78
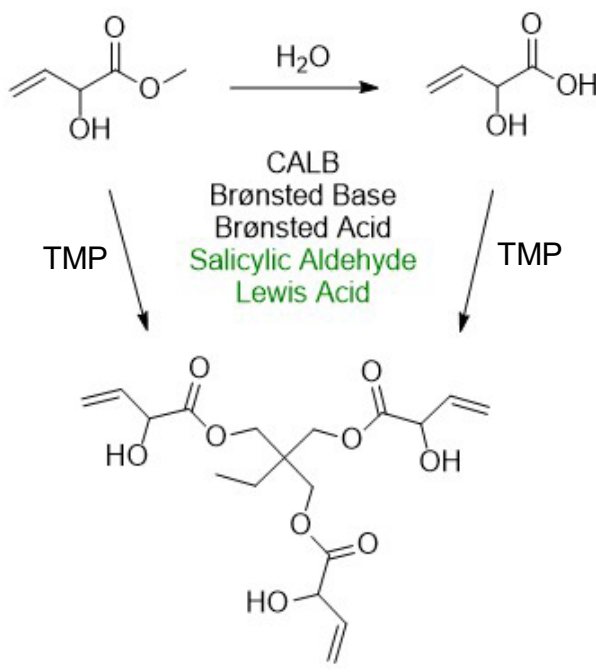


\section{Experimental}

81

82

83

84

85

86

87

88

89

90

\subsection{Materials}

MVG was kindly donated by Haldor Topsøe A/S, Candida Antarctica Lipase B (CALB) was kindly donated by Novozymes A/S and ethoxy-PE (Polyol4290) and ethoxy-TMP (Polyol3380) were kindly donated by Perstorp. All other solvents, reagents and materials were obtained commercially and used without further purification unless otherwise stated. Dry toluene and DMSO were obtained by a PureSolv ${ }^{\mathrm{TM}}$ MD-7 Solvent Purification System from Innovative Technology with $\mathrm{Al}_{2} \mathrm{O}_{3}$ as stationary phase. Vacuum of about 10 mbar was generated with an oil pump (without a manometer), and applied for the equilibrium esterification/transesterification reactions to facilitate byproduct and water removal. Anhydrous propanol and t-butanol was obtained by storing over activated $4 \AA$ molecular sieves at least $24 \mathrm{~h}$ prior to use, according to standard laboratory procedure [14].

\subsection{Methods}

NMR spectroscopy was performed on a Bruker Ascend spectrometer with a Prodigy cryoprobe operating at $400 \mathrm{MHz}$ for ${ }^{1} \mathrm{H}$ NMR and $101 \mathrm{MHz}$ for ${ }^{13} \mathrm{C}$ NMR. HSQC and $\mathrm{HMBC}$ analysis where conducted for structure validation when ${ }^{1} \mathrm{H}$ and ${ }^{13} \mathrm{C}$ NMR proved insufficient. All NMR spectra were recorded with $\mathrm{d}^{6}$-DMSO as solvent. Chemical shifts $(\delta)$ are reported in ppm downfield from TMS $(\delta=0 \mathrm{ppm})$ using solvent resonance as the internal standard $\left({ }^{1} \mathrm{H}: 2.51 \mathrm{ppm},{ }^{13} \mathrm{C}: 39.52 \mathrm{ppm}\right)$. First order coupling constants $(J)$ are reported in $\mathrm{Hz}$ when applicable. Multiplicities are reported as singlet (s), doublet (d), triplet (t), quartet (q) doublet of doublets (dd), doublet of triplets (dt) and multiplets (m).

Infrared spectra were recorded on a Bruker alpha-P FT-IR spectrometer with $4 \mathrm{~cm}^{-1}$ resolution. Peaks are reported as strong intensity (s), medium intensity (m), weak intensity (w) and broad peaks (b).

\subsection{Syntheses}


103 A $10 \mathrm{~mL}$ round bottom flask was charged with MVG (4 mmol), CALB ( $50 \mathrm{mg}$ ) and $5 \mathrm{~mL}$ distilled water. The 104 mixture was then magnetically stirred with a stirring bar at $60^{\circ} \mathrm{C}$ for $18 \mathrm{~h}$ (TLC indicated the reaction was 105 finished), where after the enzymes were removed by filtration followed by the water by rotary 106 evaporation yielding a yellowish liquid in quantitative yields. ${ }^{1} \mathrm{H} N \mathrm{NM}\left(400 \mathrm{MHz}, \mathrm{d}^{6}\right.$-DMSO) $\delta / \mathrm{ppm}: 5.94$ 107 (ddd, $J=17.2,10.4,4.9 \mathrm{~Hz}, 1 \mathrm{H}, H \mathrm{C}-\mathrm{OH}), 5.36$ (dd, $J=17.3,1.9 \mathrm{~Hz}, 1 \mathrm{H}, H C H$ ), $5.16(\mathrm{dt}, J=10.5,1.9 \mathrm{~Hz}, 1 \mathrm{H}$,

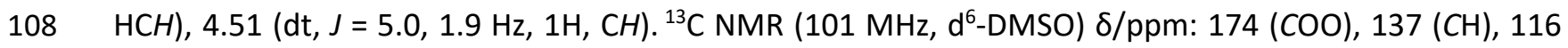
$109(\mathrm{HCH})$ and $71.5(\mathrm{HC}-\mathrm{OH})$. FTIR v/cm ${ }^{-1}: 2500-3392$ (s,b O-H stretch), 1718 (s, C=O stretch), 1642 (w, C=C stretch), 1211 (m, C-O stretch), 1138 (m, C-O stretch), 1071 (m, C-O stretch), $990 \mathrm{~cm}^{-1}$ (w, C=C-H oop).

\section{Ethoxylated PE/TMP (ethoxy-PE/ethoxy-TMP)}

112 A $10 \mathrm{~mL}$ round bottom flask was charged with MVG (4 mmol) and ethoxy-PE (Polyol 4290, $0.25 \mathrm{mmol}$ ) or 113 ethoxy-TMP (Polyol3380, $0.25 \mathrm{mmol}$ ), CALB $(50 \mathrm{mg}$ ) and $5 \mathrm{~mL}$ anhydrous toluene. A tube with activated 4 $114 \AA$ A molecular sieves was positioned on the flask, and the flask filled with $\mathrm{N}_{2}$ gas after two vacuum cycles. 115 Subsequently, the mixture was magnetically stirring with a stirring bar for $70 \mathrm{~h}\left({ }^{1} \mathrm{H}\right.$ NMR indicated the 116 reaction was finished by the peak appearing at $4.2 \mathrm{ppm})$. After reaction, the enzymes were removed by

117 filtration (by addition of acetone) and the toluene removed by rotary evaporation $\left(40{ }^{\circ} \mathrm{C}, 50 \mathrm{mbar}\right)$ to 118 obtain a transparent yellowish oil. Yield MVG-ethoxy-PE $83 \%\left({ }^{13} \mathrm{C}\right.$ NMR relative to ethoxy-PE). Yield MVG119 ethoxy-TMP 80\% ( ${ }^{1} \mathrm{H}$ NMR relative to ethoxy-TMG). 
Method using VGA and tin(II) chloride: VGA (4 mmol), TMP (1 mmol) and $\mathrm{SnCl}_{2} \cdot 2 \mathrm{H}_{2} \mathrm{O}(10 \mathrm{mg})$ was magnetically stirred in a $5 \mathrm{~mL}$ round bottom flask at $60{ }^{\circ} \mathrm{C}$ under vacuum for $40 \mathrm{~h}\left({ }^{1} \mathrm{H}\right.$ NMR indicated the reaction was finished by the peak appearing at $4.05 \mathrm{ppm})$. Yield $87.5 \%\left({ }^{13} \mathrm{C}\right.$ NMR relative to TMP).

Method using MVG and tin(II) chloride: MVG (8 mmol), TMP (1 mmol) and $\mathrm{SnCl}_{2} \cdot 2 \mathrm{H}_{2} \mathrm{O}(10 \mathrm{mg}, 1 \mathrm{mmol})$ was added to a $5 \mathrm{~mL}$ round bottom flask and the mixture magnetically stirred in closed system at $120^{\circ} \mathrm{C}$ for $18 \mathrm{~h}\left({ }^{1} \mathrm{H}\right.$ NMR indicated the reaction was finished by the peak appearing at $\left.4.05 \mathrm{ppm}\right)$. Conversion $65 \%$ $\left({ }^{13} \mathrm{C}\right.$ NMR relative to TMP).

Method using salicylic aldehyde: A $5 \mathrm{~mL}$ round bottom flask was charged with VGA ( 2 mmol), TMP (0.25 mmol), salicylic aldehyde $(0.2 \mathrm{mmol})$ and $1 \mathrm{~mL}$ anhydrous toluene. The solution was purged with $\mathrm{N}_{2}$ and subsequently magnetically stirred at $100{ }^{\circ} \mathrm{C}$ for $14 \mathrm{~h}\left({ }^{1} \mathrm{H}\right.$ NMR indicated full TMP conversion by the peak disappearing at $3.35 \mathrm{ppm})$. Yield $100 \%\left({ }^{13} \mathrm{C}\right.$ NMR relative to TMP).

The products were purified by flash column chromatography with ethyl acetate:heptane (1:1) as eluent. ${ }^{1} \mathrm{H}$ NMR (400 MHz, d $\mathrm{d}^{6}$-DMSO) $\delta / p p m ~ 5.98-5.83(\mathrm{~m}, 3.5 \mathrm{H}, \mathrm{CH}), 5.75(\mathrm{~d}, \mathrm{~J}=6.1 \mathrm{~Hz}, 2 \mathrm{H}, \mathrm{OH})$,5.56-5.45 (m, 1H, CH-oligomer) $5.37(\mathrm{dt}, J=17.2,1.8 \mathrm{~Hz}, 3 \mathrm{H}, \mathrm{HCH}), 5.19(\mathrm{dt}, J=10.4,1.6 \mathrm{~Hz}, 3 \mathrm{H}, \mathrm{HCH}), 4.7(\mathrm{~m}, 0.5 \mathrm{H}$, $\mathrm{HC}-\mathrm{OH}$, oligomer), $4.6(\mathrm{~m}, 0.5 \mathrm{H}, \mathrm{HC}-\mathrm{OH}), 4.09-3.97\left(\mathrm{~m}, 6 \mathrm{HC}\left(\mathrm{CH}_{2} \mathrm{O}-\right)_{3}\right), 1.41\left(\mathrm{q}, J=7.6 \mathrm{~Hz}, 2 \mathrm{HCCH} \mathrm{CH}_{3}\right)$ and 0.84-0.78 (m, 3H, $\left.\mathrm{CCH}_{2} \mathrm{CH}_{3}\right) .{ }^{13} \mathrm{C}$ NMR (101 MHz, d $\left.\mathrm{d}^{6} \mathrm{DMSO}\right)$ 8/ppm 172.38 (COO), 136.14 (HC), 116.72 $(\mathrm{HCH}), 71.47(\mathrm{HC}-\mathrm{OH}), 64.09\left(\mathrm{C}\left(\mathrm{CH}_{2} \mathrm{O}-\right)_{3}\right), 41.27$ (quaternary carbon), $22.73\left(\mathrm{CCH}_{2} \mathrm{CH}_{3}\right), 7.66\left(\mathrm{CH}_{3}\right) . \mathrm{FTIR}$ v/cm ${ }^{-1}: 3373$ (m,w O-H stretch), 2969 (w, C-H stretch of sp³ carbon), 1735 (s, C=O stretch of ester), 1644 ( $w, C=C$ stretch of vinyl), 1464 ( $w, \mathrm{CH}_{2}$ bend), 1387 ( $w, \mathrm{CH}_{3}$ bend), 1190 (s, C-O stretch), 1135 (s, C-O stretch), 1088 (s, C-O stretch), 987 (s, =C-H oop of vinyl), 932 (s, =C-H oop of vinyl).

Transesterification of MVG with TMP using Lewis acids 
$14220 \mathrm{~mL}$ glass tubes were charged with TMP $(0.5 \mathrm{mmol})$, MVG $(4 \mathrm{mmol})$ and a metal chloride $(0.02 \mathrm{mmol})$.

143 The glass tubes were evacuated to vacuum and positioned in a Carousel 12 Plus Reaction Station ${ }^{\mathrm{TM}}$ that $^{\mathrm{A}}$

144 was preheated to $120{ }^{\circ} \mathrm{C}$ and stirred. During reaction $(12 \mathrm{~h})$, the tubes were shortly removed from the

145 carousel every $4 \mathrm{~h}$ to take small samples $(\sim 0.05 \mathrm{~mL})$ by a syringe, which were added directly to $\mathrm{d}^{6}$-DMSO

146 in NMR tubes and stored in a fridge prior to analysis. Samples from reaction with $\mathrm{FeCl}_{2}$ and $\mathrm{YbCl}_{3}$ were

147 filtered prior to analysis to avoid severe signal broadening from metal ions.

Transesterification of MVG with TMP/PE using tin(II) chloride

149 Typically $10 \mathrm{~mL}$ round bottom flask was charged with MVG (12 mmol), TMP/PE (1.5 mmol), $\mathrm{SnCl}_{2} \cdot 2 \mathrm{H}_{2} \mathrm{O}$

150 (15 mg, $1.5 \mathrm{mmol}$ ) and evacuated to vacuum, where after it was placed in an oil bath at $120^{\circ} \mathrm{C}$ with

151 magnetically stirring. During reaction, aliquots of the reaction mixture $(\sim 0.05 \mathrm{~mL})$ were periodically

152 syringed, and added to $\mathrm{d}^{6}$-DMSO in NMR tubes. All samples were stored in a fridge prior to NMR analysis.

\section{Results and Discussion}

\subsection{Analytic method for transesterification reactions}

In order to evaluate the transesterification reactions comprehensibly, a reliable method for determination of conversion as well as the degree of acylation and oligomerization was necessary. Such analysis is not common practice within these types of reactions, however it was noticed that acylation moves the chemical shift of the quaternary carbon in ${ }^{13} \mathrm{C}$ NMR sufficiently upfield to identify each individual species. Through comparison between standard and quantitative ${ }^{13} \mathrm{C}$ NMR it was found that standard ${ }^{13} \mathrm{C}$ NMR was adequate, both for the determination of conversion and acylation degree based on integration of the quaternary carbons. By conducting HSQC and HMBC experiments, it was found that the degree of polymerization could be determined by ${ }^{1} \mathrm{H}$ NMR (see SI for detailed description). 


\subsection{Candida Antarctica Lipase B (CALB) catalyzed transesterification}

The transesterification of MVG and TMP/PE requires high chemoselectivity, especially for primary alcohols over secondary alcohols. Enzymes have emerged as sustainable catalysts with high regio- and enantioselectivity and Candida Antarctica Lipase B (CALB) has been extensively studied for the selective acylation of sugars with high selectivity reported towards the acylation of primary hydroxyl groups $[15,[16]$, while it also tolerates other functional groups such as vinyl or acrylic double bonds [17]. Moreover, secondary alcohols in the $\alpha$-position to the acyl donor are generally not reactive in CALBcatalyzed acylations [18],[19]. CALB is further known to catalyze the acylation of polyols and the transesterification of $\alpha$-hydroxy acids, thus potentially making it an ideal catalyst for the present study $[20],[21]$.

When carrying out the CALB catalyzed transesterification between MVG and TMP or PE low product yield was observed (Table 1, entry 1). However, CALB was able to catalyze the transesterification between propanol and MVG (result not shown), thereby proving that CALB was able to catalyze the transesterification with MVG as acyl donor and it is also known to catalyze the acylation of glycerol and pentaerythritol in preparation of branched molecules [22],[23]. Accordingly, it was rationalized that CALBs inability to catalyze the transesterification between MVG and TMP/PE was due to steric constrains within the active center of the enzyme. We hypothesized that by extending the length of the polyol branches the individual branches could enter the active site of the enzyme while the rest of molecule stays outside. Thus, the hydroxyl groups become more available for the enzyme despite the molecule becomes more sterically demanding at the core. When changing the polyols to the analogous ethoxylated adducts, up to $80 \%$ transesterification yields were obtained using just a 4 times molar excess of MVG in toluene (Table 1, entries 2 and 4). This supports the hypothesis that steric properties is a main issue for the reaction with polyols like TMP and PE. The ethoxylation further reduces the polarity and changes the physical state of the substrate (oils rather than solids) allowing for conducting the reaction in bulk. Unfortunately, when carrying out the reaction in bulk MVG (15-fold excess) no 
188 highly solvating molecules like DMSO and DMF [24]. This effect combined with the high viscosity of ethoxylated 189 polyols and low reaction temperatures makes CALB unsuitable for carrying out this reaction without solvents.

190 Surprisingly, a small degree of oligomerization was observed despite CALB - according to the literature [18],[21] - cannot polymerize $\alpha$-hydroxy acids.
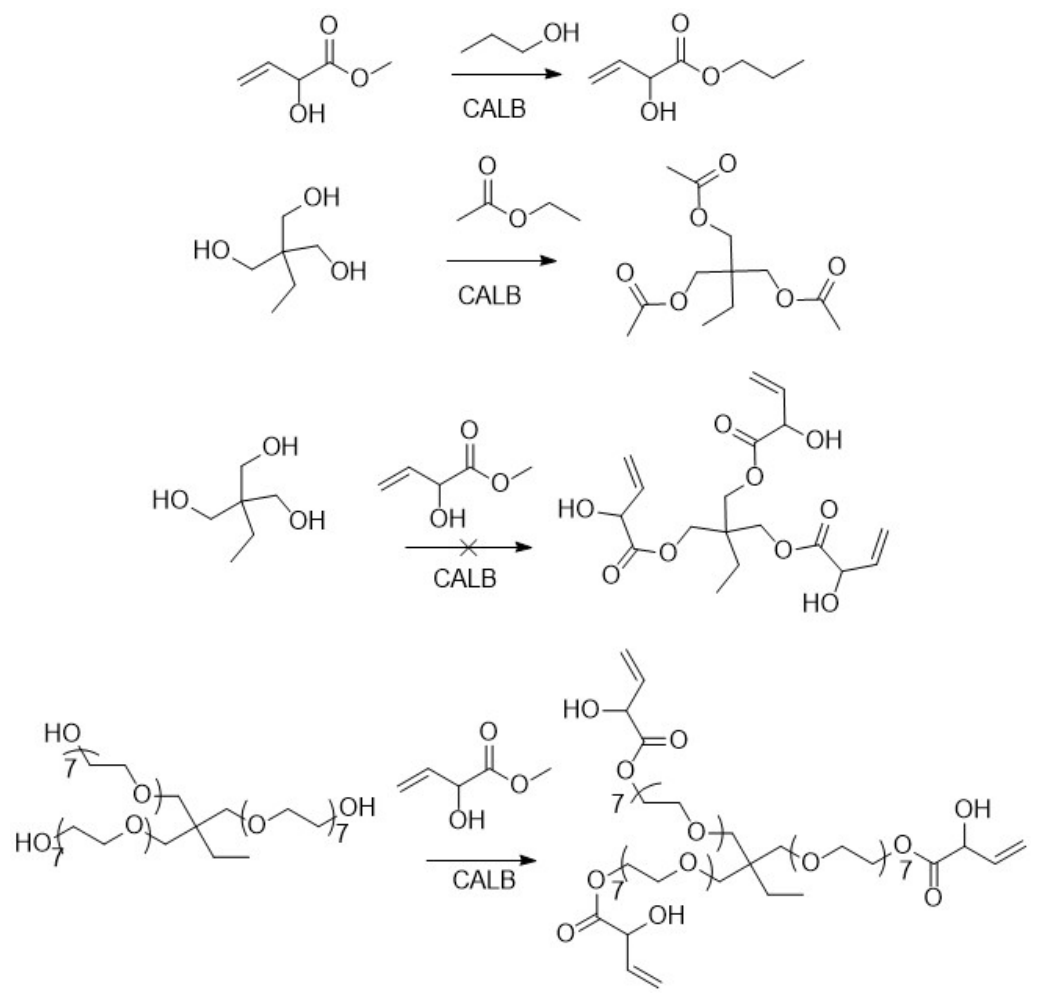

Scheme 3. CALB transesterification reactions of MVG.

\subsection{Brønsted base/acid catalyzed transesterification}

Homogeneous base catalysis is superior in the transesterifications reactions of biodiesel [25]. However,

197 VGA impurities ( 3.3\% determined by ${ }^{1} \mathrm{H}$ NMR). As MVG is also reported to dimerize with equimolar 
amounts of base, it was not surprising that the transesterification of MVG with propanol did not proceed with $5 \mathrm{~mol} \% \mathrm{KOH}$.

Transesterification of, e.g. biodiesel, is also widely applied using homogeneous acid catalysis due to the robustness of acids against typical impurities (acid and water) [25]. In line with this, sulfuric acid actively catalyzed the transesterification between MVG and propanol (Table 1, entry 5), but unfortunately also produced copious amounts of unwanted byproducts in high yields making the system useless.

\subsection{Salicylic aldehyde catalyzed (trans)esterification}

Outside of the typical transesterification catalysts, salicylic aldehyde has been found to irreversibly catalyze the esterification process of $\alpha$-hydroxy acids [26]. Salicylic aldehyde proved very efficient in catalyzing the esterification process between VGA and TMP resulting in quantitative yield with only 2.66 times VGA excess (Table 1, entry 6). This is quite impressive as esterification reactions are typically carried out with more than 10-fold excess of one of the substrates and removal of the produced byproducts to obtain high conversions [27]. Unfortunately, salicylic aldehyde could not catalyze the process with MVG as acyl donor, deeming it necessary to carry out a hydrolysis step to VGA before its eventual use. Although the hydrolysis step potentially is easy to do also in a larger (industrial) setting, it would probably be undesirable as it also introduces an accompanying energy consuming purification step.

\subsection{Lewis acid catalyzed transesterification}

\section{Tin(II) chloride}

We hypothesized that tin(II) chloride would be a good Lewis acid catalyst for this reaction as tin(II) compounds are known to be efficient Lewis acid catalysts for transesterification and esterification reactions and, as previously mentioned, co-polymerization of lactic acid and VGA was achieved using tin(II) 
chloride [6],[27],[28]. When $\mathrm{SnCl}_{2} \cdot 2 \mathrm{H}_{2} \mathrm{O}$ was used as catalyst for the esterification of MVG in the present study, the reaction was also found to proceed quite selectively under benign conditions reaching full conversion with equimolar amount of VGA and PE (based on $\mathrm{OH}$ groups) at $60{ }^{\circ} \mathrm{C}$ with vacuum in $43 \mathrm{~h}$

222 (Table 1, entry 8), while higher temperatures led to undesired evaporation of VGA. Similarly, was the 223 triacylated TMP derivative also successfully synthesized (Table 1, entry 9). On the other hand, in the transesterification MVG proved too volatile to carry out the direct transesterification under those conditions $\left(60^{\circ} \mathrm{C}\right.$, vacuum), and only $45 \%$ conversion was reached after $74 \mathrm{~h}$ without the applied vacuum.

226 However, by increasing the reaction temperature to $120^{\circ} \mathrm{C}$ it proved possible, in the closed system, to 227 significantly increase the rate of the transesterification, while maintaining limited oligomerization and 228 MVG evaporation, and obtain $75 \%$ conversion within $13 \mathrm{~h}$ with just a 2.66 -fold molar excess of MVG to 229 TMP (Table 1, entries 13 and 1 and Figure 1). Despite the reaction being solvent free, the reaction rate 230 appeared to be independent of the conversion as well as the acylation degree. Moreover, oligomerization occurred only in miniscule amounts with average degree of polymerization (DP) below 1.3 and DP of oligomerized MVG units stabilizing around 2, indicating that $20 \%$ of the MVG molecules had dimerized.

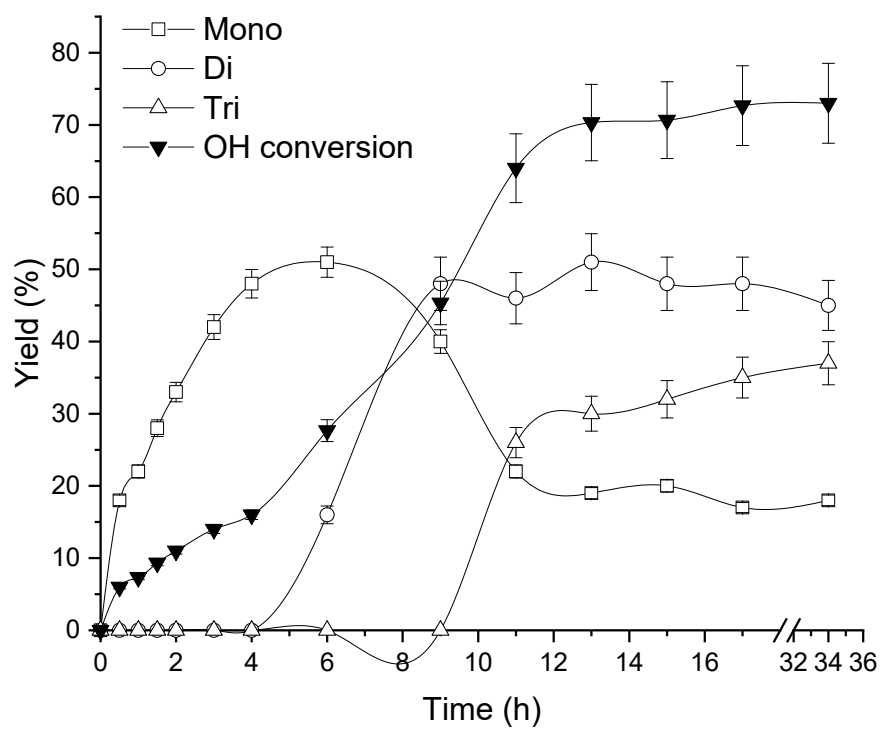


234 Figure 1. Product distribution plot of mono-, di- and triacylated TMP in the transesterification of MVG and

235 TMP in closed system with tin(II) chloride as catalyst. Reaction conditions: $1.5 \mathrm{~mol} \% \mathrm{SnCl}_{2} \cdot 2 \mathrm{H}_{2} \mathrm{O}, 2.66 \mathrm{MVG}$

236 to TMP ratio (based on $\mathrm{OH}$-groups), $120^{\circ} \mathrm{C}$.

Surprisingly, when carrying out the analogous tin(II) catalyzed transesterification reaction with PE the $\mathrm{OH}$ conversion reaches a plateau after approximately just $1 \mathrm{~h}$ albeit at a conversion of only about $50 \%$

239 (Figure 2). Similarly, the reaction rate did apparently not change as function of conversion nor did the 240 acylation degree and oligomerization was negligible. In order to obtain higher conversion, vacuum-heat 241 cycles was attempted where evaporation of MVG was avoided by cooling the reaction mixture to room 242 temperature before applying vacuum for $2 \mathrm{~h}$ followed by $2 \mathrm{~h}$ stirring at $120^{\circ} \mathrm{C}$. The two first cycles 243 increased the conversion approximately $10 \%$ per cycle, but oligomerization increased simultaneously thus 244 providing a lower overall yield.

The rapid reaction kinetics of PE compared to TMP was unexpected considering the similarity of the 246 molecules. The difference could possibly be a coordinative effect originating from the fourth hydroxyl 247 group of $\mathrm{PE}$, however, since the reaction rate was not dependent of the acylation degree (which should markedly affect the coordinative properties), the observed reactivity difference could be related to 249 properties such as, e.g. solubility and viscosity (i.e. diffusion). 


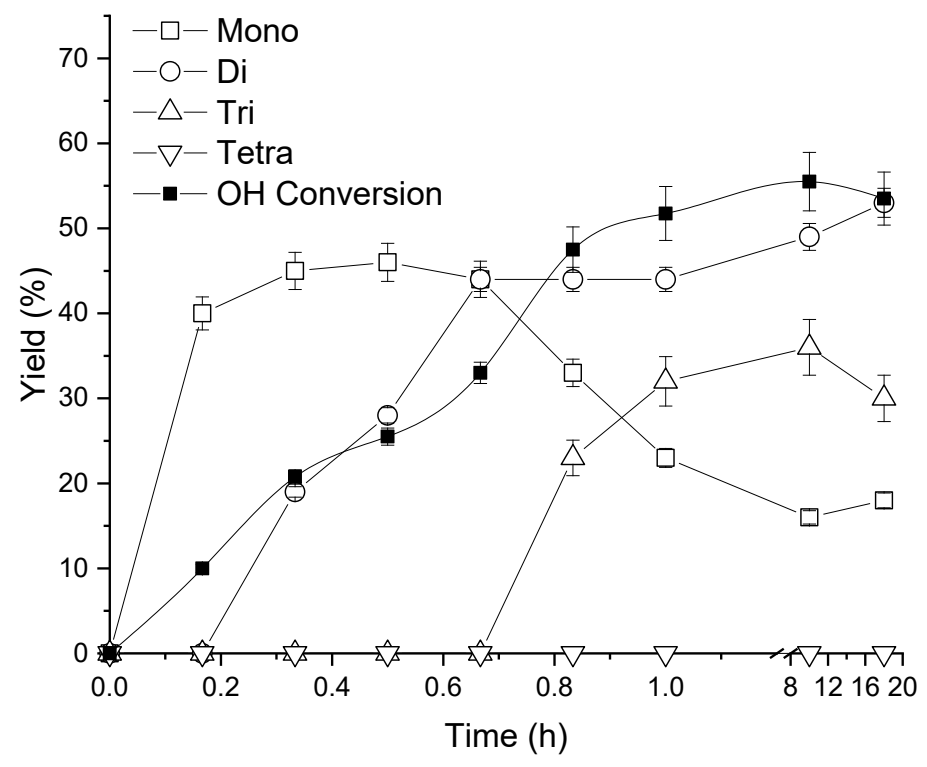

251 Figure 2. Product distribution plot of mono-, di-, tri- and tetraacylated PE in the transesterification of MVG and

$252 \mathrm{PE}$ in closed system with tin(II) chloride as catalyst. Reaction conditions: $1.5 \mathrm{~mol} \% \mathrm{SnCl}_{2} \cdot 2 \mathrm{H}_{2} \mathrm{O}, 2.66 \mathrm{MVG}$ to PE 253 ratio (based on $\mathrm{OH}$-groups), $120^{\circ} \mathrm{C}$. 
Table 1 Esterification/transesterification of VGA/MVG with polyols using different catalyst systems at optimized conditions

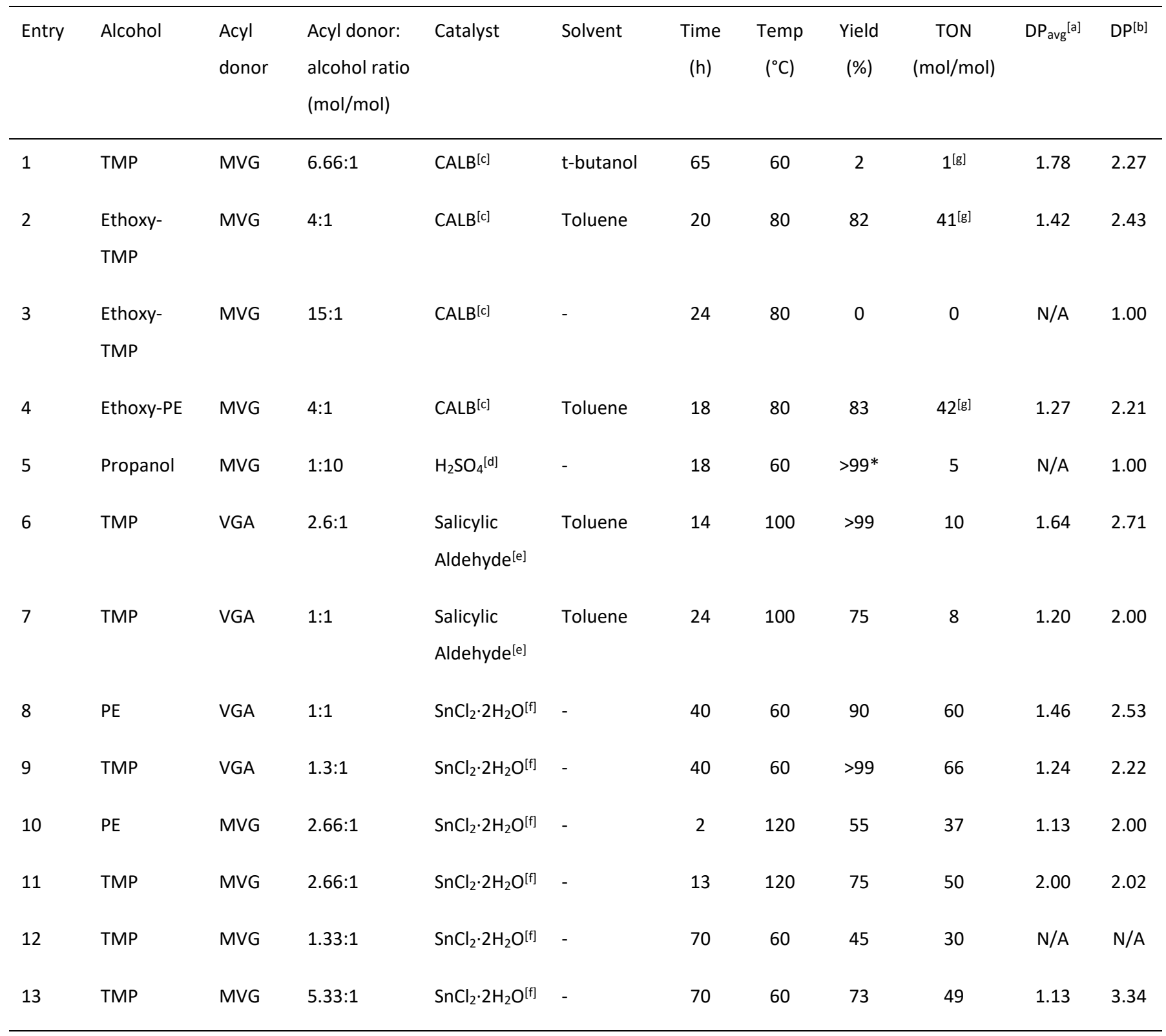

[a] DP avg: Degree of polymerization including unreacted (with regard to MVG homo condensation) MVG. [b] DP: Degree of polymerization excluding unreacted (with regard to MVG homo condensation) MVG. [c] $50 \mathrm{mg}$ CALB. [d] One drop, i.e. about $0.01 \mathrm{~mL}$. [e] $10 \mathrm{~mol} \%$. [f] 1.5 mol\%. [g] Turn over number given as mmol/100 mg catalyst, as the catalyst loadings by supplier was not provided in mol/g. *: Conversion rather than yield and a range of unidentified side products. Data based on NMR spectra, see SI Figures S24-S46 
261 The good performance of tin(II) chloride for the transesterification of MVG and TMP, without forming 262 notable side products, prompted us to investigate other Lewis acidic metal chloride catalysts for the 263 reaction. Based on the good results of tin(II) chloride, the more acidic tin(IV) chloride was examined despite it not being a typical transesterification catalyst [29], while aluminium(III) chloride, zinc(II) chloride and ytterbium(III) chloride was selected as they are more common Lewis acids. Chromium(III) chloride are in rare and specific cases an efficient transesterification catalyst [30],[31], whereas iron(II) chloride was chosen to have an untypical transesterification catalyst in the study. The ${ }^{13} \mathrm{C}$ NMR signal pattern in the $\delta$ 40-46 ppm range was characteristic for the MVG-TMP product mixture obtained in the tin catalyzed reactions (Figure 3), and allowed to estimate the conversions for the other metal chlorides. The additional signals at $\delta 159-164 \mathrm{ppm}$ were indicate of the byproducts.

271

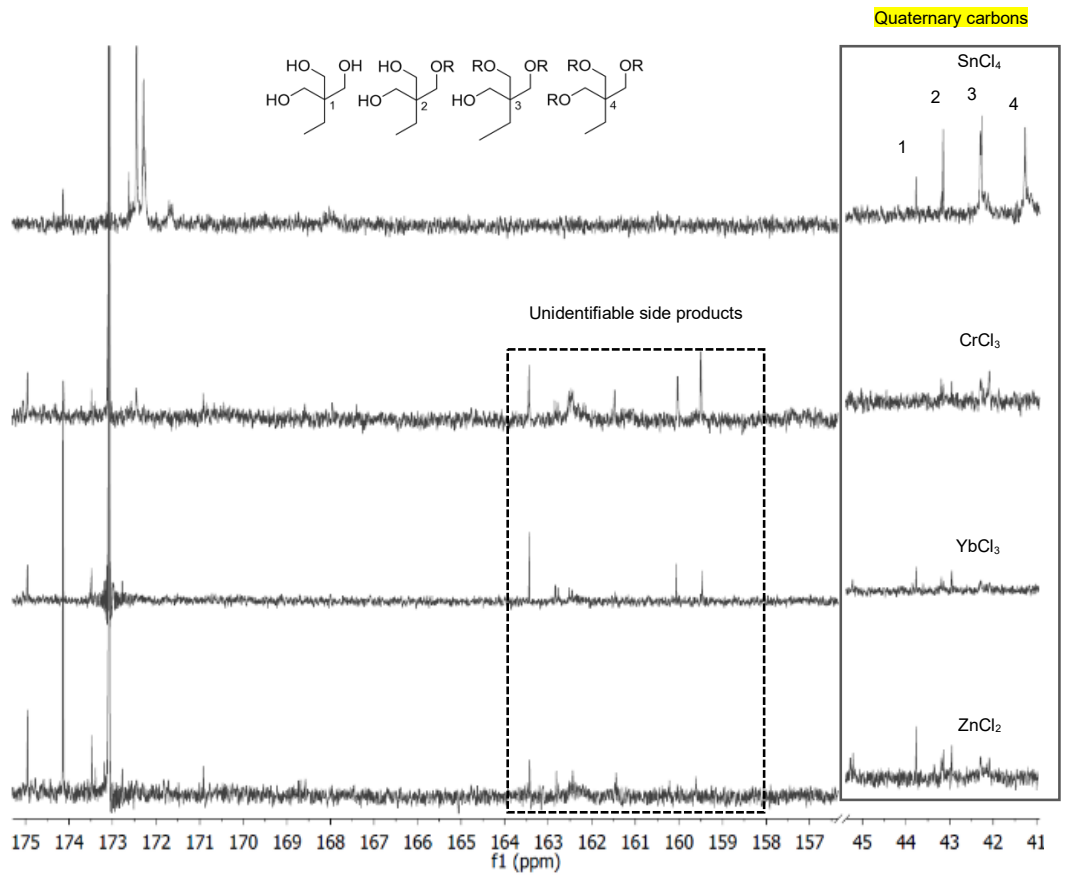


279 Figure 3. ${ }^{13} \mathrm{C}$ NMR spectra of the products after transesterification between MVG and TMP in closed 280 system with various metal chloride catalysts. Reaction conditions: 1.33 mol\% metal chloride, $2.66 \mathrm{MVG}$ to 281 TMP ratio (based on $\mathrm{OH}$-groups), $120^{\circ} \mathrm{C}, 12 \mathrm{~h}$.

As summarized in Figure 4, most of the catalysts based on alternative metals than tin yielded only moderate conversions in the reaction as well as a range of byproducts (unidentified), as also found for $\mathrm{H}_{2} \mathrm{SO}_{4}$ (see above) though even more prominent. The lower catalytic activity observed for these catalysts, including the strong Lewis acid aluminum(III) chloride which performed quite poor, could be related to 286 their limited solubility as only the tin halides efficiently dissolved in the TMP/MVG media under the applied reaction conditions. Thus, unfortunately the difference in solubility complicated the direct comparison between activity and acidity. Nevertheless, it was evident that tin chlorides was superior for this reaction. Notably, tin(IV) chloride was apparently found to be significantly more active than tin(II) chloride for the reaction allowing it to reach a final product yield of $\sim 75 \%$ within $4-8 \mathrm{~h}$ instead of $12 \mathrm{~h}$. This could be correlated to tin(IV) being a stronger Lewis acid and harder metal species than tin(II), thereby 292 facilitating reaction with the oxygen-rich substrates. Interestingly, similar superior reactivity of $\operatorname{tin}($ IV)/tin(II) salts have also previously been found in formation of $\alpha$-hydroxy acids from tetroses [4]. The superior performance of the tin chlorides was partly ascribed to their complete dissolution in the reaction 295 mixture (see above). Thus, if presence of tin chloride is undesired in the product a filtration through silica with an appropriate solvent would be necessary. However, this would make reusability of the catalyst cumbersome and a further development of the process could therefore instead target investigation of a suitable heterogeneous tin catalyst, where catalyst recycling is easy by simple filtration. 


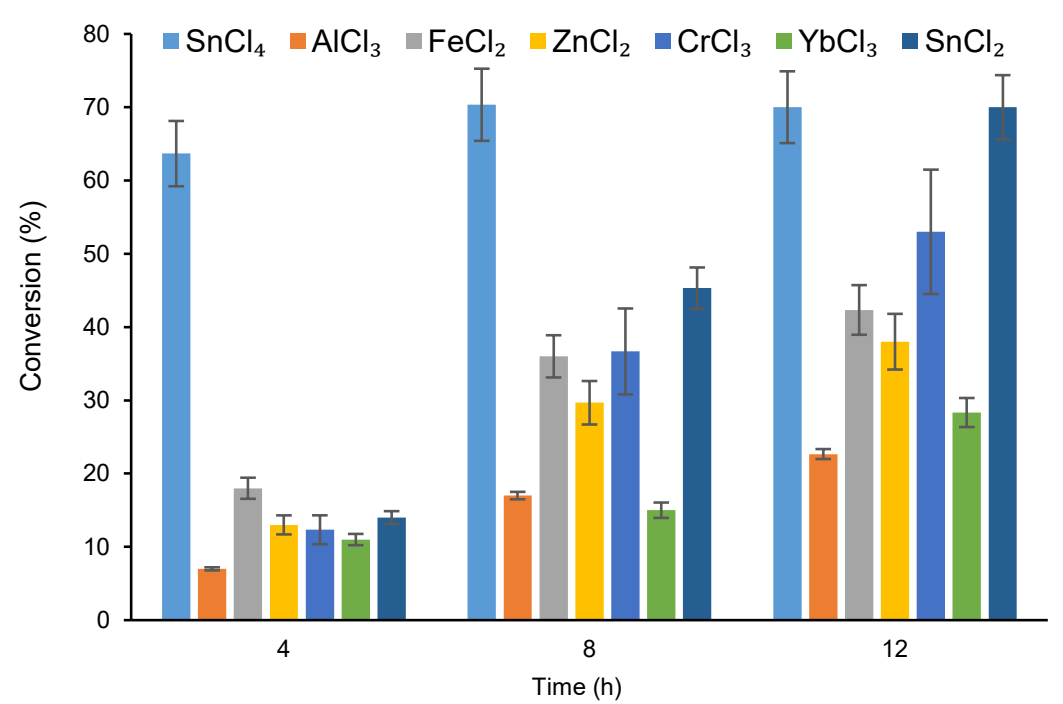

Figure 4. Yields from the transesterification of TMP and MVG with various metal chlorides in closed system. Reaction conditions: 1.33 mol\% catalyst, $2.66 \mathrm{MVG}$ to TMP ratio (based on $\mathrm{OH}$-groups), $120^{\circ} \mathrm{C}$.

\section{Conclusions}

A catalytic and benign method for the synthesis of a unique class of polyhydric derivatives - with multiple

311 functionalities - based on the novel bio-based molecule MVG were successfully developed. Salicylic

312 aldehyde catalyzed the esterification process to provide the triacylated VG derivative of TMP in excellent 313 yield with negligible oligomerization from VGA. Tin chlorides efficiently catalyzed the direct 314 transesterification process from MVG, whereas other Lewis acidic metal chlorides provided low activity 315 and selectivity. Furthermore, CALB was found to catalyze the transesterification process with ethoxylated polyols, albeit high MVG concentrations inactivated the enzyme. Overall, the reported work demonstrates

317 that novel MVG derivatives of polyols can be synthesized with negligible oligomerization under benign and solvent free conditions with low MVG excess by use of catalysts with tin(IV) chloride being superior.

319 The new MVG derivatives with a secondary hydroxyl group could possibly find use in coating systems, 
320 adhesives or as additives, where a hydrophilic surface is required or the hydroxyl groups functionalized to

321 comply with other specialized polymer properties.

\section{Acknowledgements}

323 This work was funded by the Innovation Fund Denmark (case number 5150-00023B). $800 \mathrm{MHz}$ NMR

324 spectra were recorded by using the spectrometer of the NMR center DTU supported by the Villum 325 foundation.

\section{Conflict of interest}

327 The authors declare that they have no conflict of interest.

\section{References}

329 [1] Elliot SG, Andersen C, Tolborg S, Meier S, Sádaba I, Daugaard AE, Taarning E (2017) RSC Adv. 7: $985-996$.

330 [2] Bozell JJ, Petersen GR (2010) Green Chem. 12: 539-554.

331 [3] Holm MS, Saravanamurugan S, Taarning E (2010) Science 328: 602-605.

332 [4] Dusselier M, Van Wouwe P, deClippel F, Dijkmans J, Gammon DW, Sels BF (2013) ChemCatChem 5: 569333575

334 [5] Sølvhøj A, Taarning E, Madsen R (2016) Green Chem. 18: 5448-5455.

335 [6] Dusselier M, Van Wouwe P, De Smet S, De Clercq R, Verbelen L, Van Puyvelde P, Du Prez FE, Sels BF (2013) ACS Catal. 3: 1786-1800.

337 [7] Dewaele A, Meerten L, Verbelen L, Eyley S, Thielemans W, Van Puyvelde P, Dusselier M, Sels B (2016) $338 \quad$ ACS Sustainable Chem. Eng. 4: 5943-5952.

339 [8] https://info.topsoe.com/biochemicals (Topsoe MOSAIK ${ }^{\mathrm{TM}}$ solution), accessed April 28,2020.

340 [9] Li H, Zhao W, Saravanamurugan S, Dai W, He J, Meier S, Yang S, Riisager A (2018) Commun. Chem. 1:32, 
1-11.

342 [10] Nameer S, Larsen DB, Duus J $\varnothing$, Daugaard AE, Johansson M (2018) ACS Sustainable Chem. Eng. 6: $9442-$ 9450.

[11] Günduz G, Chemistry, Materials and Properties of Surface Coatings, DEStech Publications, Inc, 215AD, 345 2016.

[12] Panchal TM, Patel A, Chauhan DD, Thomas M, Patel JV (2017) Renew. Sustain. Energy Rev. 70: 65-70.

[13] Wolfang P, Hauer B, Haring D, Dietsche F (2006) Enzymatic Synthesis of Polyol Acrylates, US20060030013A1.

[14] Amerigo WL, Chai C (2009) Purification of Laboratory Chemicals, 6. ed, Elsevier.

350

[15] Haraldsson GG, Gudmundsson, BÖ, Almarsson Ö (1995) Tetrahedron 51: 941-952.

[16] Kulshrestha, AS, Gao W, Gross RA (2005) Macromolecules 38: 3193-3204.

[17] Hoffmann C, Stuparu MC, Daugaard A, Khan A (2015) J. Polym. Sci. Part A Polym. Chem. 53: 745-749.

[18] Anderson EM, Larsson KM, Kirk O (1998) Biocatal. Biotransformation 16: 181-204.

354 [19] Li G, Yao D, Zong M (2008) Eur. Polym. J. 44: 1123-1129.

[20] Cavalcanti EDC, Aguieiras ÉCG, da Silva PR, Duarte JG, Cipolatti EP, Fernandez-Lafuente R, da Silva JAC, Freire DMG (2018) Fuel 215: 705-713.

357 [21] From M, Adlercreutz P, Mattiasson B (1997) Biotechnol Lett. 19: 315-317.

[22] Happe M, Kouadio M, Treanor C, Sawall JP, Fornage A, Sugnaux M, Fischer F (2014) J. Mol. Catal. B Enzym. 109: 40-46.

360 [23] Nguyen HD, Löf D, Hvilsted S, Daugaard AE (2016) Polymers 8: 363.

361 [24] Nott K, Brognaux A, Richard G, Laurent P, Favrelle A, Jérôme C, Blecker C, Wathelet JP, Paquot M, Deleu M (2012) Prep. Biochem. Biotechnol. 42: 348-363.

363 [25] Lam MK, Lee KT, Mohamed AR (2010) Biotechnol. Adv. 28: 500-518.

364 [26] Weng SS, Li HC, Yang TM (2013) RSC Adv. 3: 1976-1986.

365 [27] Ferreira AB, Lemos Cardoso A, da Silva JM (2012) ISRN Renew. Energy 2012: 1-13. 
366 [28] Casas A, Ramos MJ, Rodríguez JF, Pérez Á (2013) Fuel Process. Technol. 106: 321-325.

367 [29] Patel Y, George J, Pillai SM, Munshi P (2009) Green Chem. 11: 1056-1060.

368 [30] Cao J, Qi B, Liu J, Shang Y, Liu H, Wang W, Lv J, Chen Z, Zhang H, Zhou X (2016) RSC Adv. 26: 2161236921616.

370 [31] Reddy CR, lyengar P, Nagendrappa G, Prakash BSJ (2005) J. Mol. Catal. A Chem. 229: 31-37. 